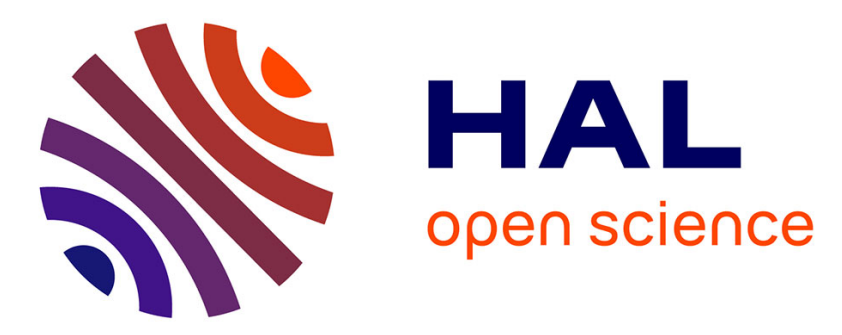

\title{
Permeability dependence of streaming potential in rocks for various fluid conductivities
}

Laurence Jouniaux, Jean-Pierre Pozzi

\section{To cite this version:}

Laurence Jouniaux, Jean-Pierre Pozzi. Permeability dependence of streaming potential in rocks for various fluid conductivities. Geophysical Research Letters, 1995, 22 (4), pp.485-488. 10.1029/94GL03307 . hal-00108308

\section{HAL Id: hal-00108308 \\ https://hal.science/hal-00108308}

Submitted on 16 Nov 2011

HAL is a multi-disciplinary open access archive for the deposit and dissemination of scientific research documents, whether they are published or not. The documents may come from teaching and research institutions in France or abroad, or from public or private research centers.
L'archive ouverte pluridisciplinaire HAL, est destinée au dépôt et à la diffusion de documents scientifiques de niveau recherche, publiés ou non, émanant des établissements d'enseignement et de recherche français ou étrangers, des laboratoires publics ou privés. 


\title{
Please, cite this article as :Jouniaux L. and Pozzi J.-P., Permeability dependence of streaming potential in rocks for various fluid conductivities, Geophys. Res. Letters., 22, 485-488, 1995 \\ contact: 1.jouniaux@unistra.fr \\ Permeability dependence of streaming potential in rocks for various fluid conductivities
}

\author{
Laurence Jouniaux and Jean-Pierre Pozzi \\ Laboratoire de Géologie \& CNRS URA 1316, École Normale Supérieure, Paris, France.
}

\begin{abstract}
Streaming potentials have been measured on sandstone and limestone samples in a large range of permeabilities. The electrokinetic coupling coefficient increases with permeability and we explain this effect by the related variation of surface conductivity. A model is proposed to study this effect for various fluid conductivities and it is shown that the dependence of the electrokinetic coupling coefficient on permeability is stronger for high fluid resistivity and is weaker for lower fluid resistivity. When fluid resistivity is below $1 \Omega$.m permeability and streaming potential are no more related.
\end{abstract}

\section{Introduction}

Observations of self-potential (SP) anomalies by surface measurements have been reported from numerous tectonically active areas in the world. The streaming potential effect in the crust may be promising to explain low frequency electric and magnetic precursors to earthquakes [Mizutani et al., 1976; Bernard, 1992]. Electrokinetic effects are often proposed to explain SP anomalies on volcanoes [Zlotnicki and Le Mouël, 1990; Aubert and Dana, 1994] and in geothermal areas [Corwin and Hoover, 1979], or used to monitor subsurface flow in geotechnical constructions [Merkler et al., 1989]. Streaming potentials can be quantified through experimental results. Few streaming potential data of geophysical interest are available [Somasundaran and Kulkarni, 1973; Ishido and Mizutani, 1981; Morgan et al., 1989; Antraygues and Aubert, 1993]. Effects of high pressure, high temperature, or changes of permeability on streaming potential have not been systematically analysed. Note that permeability varies by 11 orders of magnitude in the Earth's crust and can vary by 5 orders of magnitude in a given geological layer. We present streaming potential measurements on sandstone and limestone samples covering a large range of permeabilities and we propose a model to quantify the effect of permeability on streaming potential with various fluid conductivities.

\section{Electrokinetic phenomena}

When a fluid is made to flow through a porous medium there is an occurence of a potential called streaming potential across the sample caused by the relative motion between the solid and the liquid. Electrokinetic phenomena are due to the existence of an electric double layer formed at the solid-liquid interface [Stern, 1924]. The double layer is made up of a layer of ions adsorbed on the surface of the matrix and of a diffuse mobile layer extending into the liquid phase. The zeta potential is the electric potential on the plane closest to the surface of the matrix on which fluid is in motion. Phenomenologically the general relation between the electric current density i and the thermodynamical forces grad V and grad P [Overbeek, 1952; Nourbehecht, 1963] is from irreversible thermodynamics

$\mathrm{i}=-\mathrm{L}_{11} \operatorname{grad} \mathrm{V}-\mathrm{L}_{12} \operatorname{grad} \mathrm{P}\left(\mathrm{A} / \mathrm{m}^{2}\right)$

where $\mathrm{P}$ is the pore pressure, $\mathrm{V}$ the electric potential, $\mathrm{L}_{11}$ the conductivity and $\mathrm{L}_{12}$ the cross-coupling coefficient. The first term is the conduction current (Ohm's law) and the second term is called convection 
current. Ishido and Mizutani [1981] used a capillary model to formulate the electrokinetic phenomena in porous media. The specific conductivity of the sample $\sigma_{\mathrm{r}}$ has been expressed in terms of tortuosity $\mathrm{t}$ (actual flow path/bulk length measure), porosity $\Phi$, specific internal area $A_{s}$ (total internal pore surface area/volume of the sample), and specific surface conductance $\mathrm{k}_{\mathrm{s}}$ (assumed to be due to the excess ions in the electrical double layer) assuming identical tortuosity for bulk and surface conduction and for fluid flow :

$\mathrm{L}_{11}=\sigma_{\mathrm{r}}=\Phi \mathrm{t}^{-2} \sigma_{\mathrm{f}}+\mathrm{t}^{-2} \mathrm{k}_{\mathrm{s}} \mathrm{A}_{\mathrm{s}} \quad$ [Pfannkuch, 1972]

$\mathrm{L}_{12}=-\Phi \mathrm{t}^{-2} \varepsilon \zeta / \eta$

[de Groot and Mazur, 1962]

where $\sigma_{\mathrm{f}} \varepsilon$ and $\eta$ are the electric conductivity, the electric permittivity and the shear viscosity of fluid, and $\zeta$ the zeta potential. In a steady state equilibrium the convection current is balanced by the conduction current and the generated potential DV is related to the applied pore pressure difference DP by

$\mathrm{DV} / \mathrm{DP}=\varepsilon \zeta /\left[\eta\left(\sigma_{\mathrm{f}}+\mathrm{k}_{\mathrm{s}} \mathrm{A}_{\mathrm{s}} / \Phi\right)\right]$

The ratio DV/DP is the electrokinetic coupling coefficient which is independant on the size of the specimen under consideration. When surface conductivity is absent $\mathrm{k}_{\mathrm{s}} \mathrm{A}_{\mathrm{s}} / \Phi$ is negligible compared to $\sigma_{\mathrm{f}}$, then DV/DP $=\varepsilon \zeta / \eta \sigma_{\mathrm{f}}$ which is the Helmholtz-Smoluchowski equation [Dukhin and Derjaguin, 1974]. Note that DV/DP can be positive or negative depending on the sign of $\zeta$ potential.

\section{Experimental procedure}

The relation between permeability $\mathrm{k}$ and streaming potential was investigated on saturated limestone and Fontainebleau sandstone samples. Fontainebleau sandstones do not contain clay and show uniform sized quartz grains ranging from 100 to $300 \mathrm{~mm}$. Measurements on sandstones have been made on intact samples covering a large range of permeabilities from $1.5 \times 10^{-16} \mathrm{~m}^{2}$ to $1.2 \times 10^{-12} \mathrm{~m}^{2}$. One sample of limestone has been studied during permeability changes under deformation. An increasing deviatoric stress was applied to this sample and C12, C11, C10 refer to three states of deformation of the limestone sample. This sample was collected in an underground quarry where SP measurements have been clearly correlated with changes of the atmospheric pressure [Morat and Le Mouël, 1992]. The streaming potential was measured during fluid flow by a voltmeter with an input resistance above $10^{10} \Omega$.m. Permeability was measured either by the steady state flow method or the transient flow method. The resistance of the sample was measured by an impedancemeter at $4 \mathrm{kHz}$ frequency. The high pressure cell and the experimental procedure have been detailed in [Jouniaux and Pozzi, in press]. The streaming potential was measured on sandstones with distilled water of $\mathrm{pH}=5$ and resistivity $\mathrm{r}_{\mathrm{f}}=1000 \Omega$.m, and on limestone with water resistivity of $200 \Omega$.m.

\section{Experimental results}

The formation factor was computed from the measurements of the rock resistivity and of the fluid resistivity $\left(\mathrm{FF}=\mathrm{r}_{\text {rock }} / \mathrm{r}_{\text {fluid }}\right)$. The c factor is a numerical constant determined by the actual pore shape [Wyllie and Spangler, 1952] ( 0.5 for circular pores, 0.6 for equilateral triangular cross-section, 0.33 for a slot) was deduced from the observed thin sections (Table 1).We observed negative electrokinetic coupling coefficients in all these experiments; the reported values are the absolute values of the electrokinetic coupling coefficient. The electrokinetic coupling coefficients measured on Fontainebleau sandstones are shown in figure 1 (empty squares). 


\begin{tabular}{|c|c|c|c|c|c|c|}
\hline S & $\Phi$ & $\mathrm{k}$ & $\mathrm{FF}$ & C & DV/DP & DV/DP \\
\hline F82 & $4.3 \%$ & 0.15 & 16.7 & 0.33 & $\begin{array}{l}\text { meas. } \\
11\end{array}$ & $\begin{array}{l}\text { comp. } \\
65\end{array}$ \\
\hline$\overline{\mathrm{C} 10}$ & & 1.1 & 1.8 & 0.5 & 17.1 & $\begin{array}{l}18.9 \\
\end{array}$ \\
\hline C11 & & 2.6 & 2.6 & 0.5 & 23.4 & 26.3 \\
\hline F17 & & 5 & & & 65 & \\
\hline F01 & & 86 & & & 310 & \\
\hline C12 & $37 \%$ & 156 & 3.3 & 0.5 & 55.6 & 44.6 \\
\hline F9IY & $9.9 \%$ & 180 & 36 & 0.5 & 1166 & 1199 \\
\hline FK5 & $10 \%$ & 250 & 158 & 0.5 & 4002 & 2337 \\
\hline F34 & $11.9 \%$ & 250 & 30.6 & 0.5 & 1287 & 1221 \\
\hline F44 & $13 \%$ & 287 & 45 & 0.5 & 661 & 1642 \\
\hline F2 & $20 \%$ & 1220 & 77 & 0.5 & 6642 & 3011 \\
\hline
\end{tabular}

Table 1. Characterisation of the samples. F are sandstones and $\mathrm{C}$ are limestone. Permeability $\mathrm{k}$ is in $10^{-15} \mathrm{~m}^{2}$ and DV/DP measured and computed are in $\mathrm{mV} / 0.1 \mathrm{MPa}$.

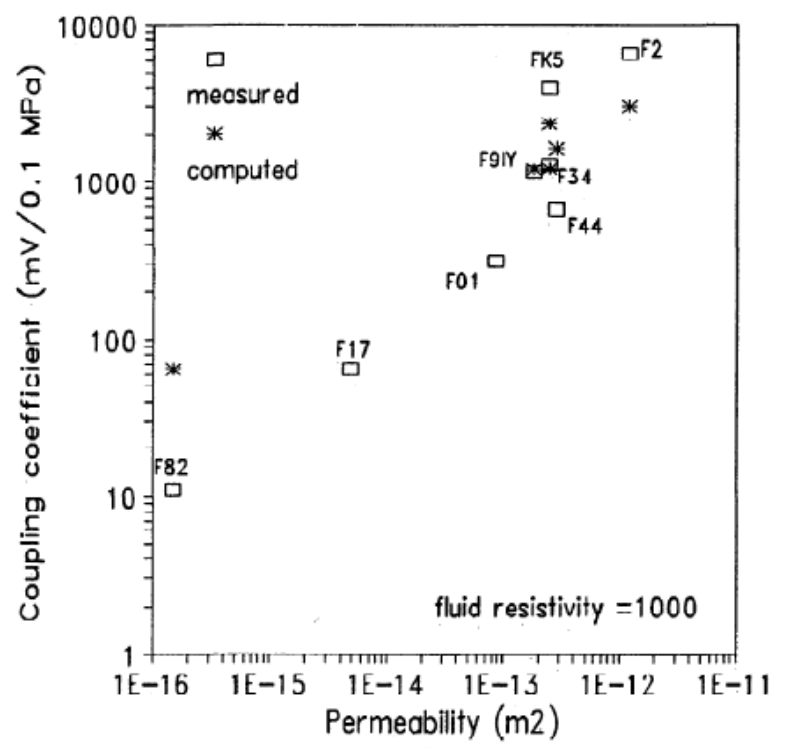

Figure 1. Electrokinetic coupling coefficient as a function of permeability when fluid resistivity is $1000 \Omega$.m. Empty squares are measured values and stars are computed values from eq.(5).

The electrokinetic coupling coefficients measured on a limestone sample are shown in figure 2 (empty squares). These measurements show an electrokinetic coupling coefficient proportional to $\mathrm{k}^{0.23}$. 


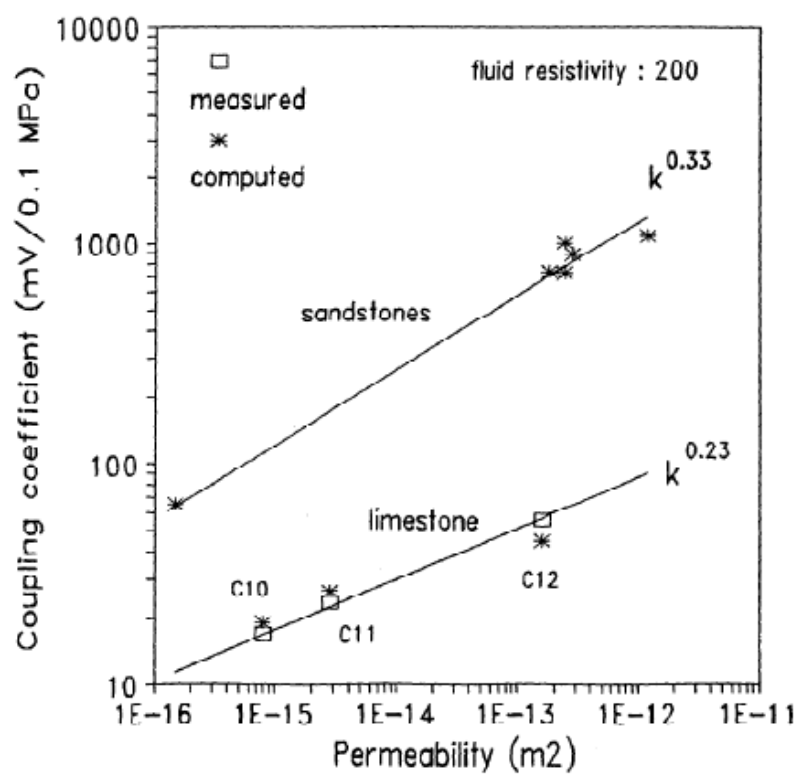

Figure 2. Electrokinetic coupling coefficient as a function of permeability when fluid resistivity is $200 \mathrm{~W}$.m. Empty squares are measured values for the limestone, stars are computed values from eq.(5) and slopes of straightlines are proportional to $\mathrm{k}^{0.33}$ and to $\mathrm{k}^{0.23}$.

\section{Model}

We explain this behavior by the effect of surface conductivity. Surface conductivity can be important when fluid resistivity is high or when pore size $r$ is not large compared to the Debye length $\kappa^{-1}$ (double layer length)

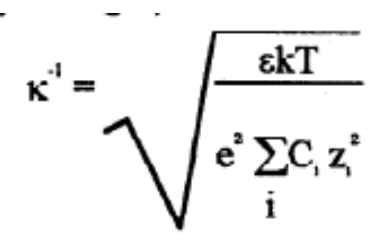

where $z_{i}$ is the valence of the ionic species with concentration $C_{i}$, $k$ is the Boltzman's constant, $T$ the temperature and e the electronic charge. Note that the Debye length is proportional to the square root of the fluid resistivity.

Bröz and Epstein [1976] have measured that surface conductivity in borosilicate glass capillaries with $\zeta$ potential of about $55 \mathrm{mV}$ is not negligible for $\mathrm{kr}$ up to 40. The authors compared their measurements to the model from Rice and Whitehead [1965] and Levine et al. [1975] who computed that surface conductivity was not negligible for $\mathrm{kr}$ up to 100 in some cases : the $\mathrm{z}$ potential deduced from the HelmholtzSmoluchowski equation can be underestimated of a few \% when $\mathrm{kr}=100$, of $20 \%$ when $\mathrm{kr}$ is about $15-25$ and of $40 \%$ when $\mathrm{\kappa r}$ is about $5-10$.

In our case the distilled water with $\mathrm{pH}=5$ induces a Debye length of $0.13 \mathrm{~mm}$. The sample $\mathrm{F} 2$ which is the most permeable one has an average pore size of $50 \mu \mathrm{m}$. Therefore $\mathrm{\kappa r}=385$ and we assumed that surface conductivity was not important for this sample. $\zeta$ potential was then computed from the Helmholtz- 
Smoluchowski equation for the sample F2 and was found to be $-97 \mathrm{mV}$. This value is consistent with other values of $\zeta$ potential on quartz deduced from measurements or from theory [Li and De Bruyn, 1966; Pride and Morgan, 1991]. Furthermore $\zeta$ potential is expected to be of the same order of magnitude for all these Fontainebleau sandstones because the mineralogy is nearly identical. As the other samples have smaller pore size we assumed that surface conductivity was present. The smaller the permeability is, the smaller the pore sizes in sandstones are expected to be, and the apparent dependence of the electrokinetic coupling coefficient on permeability can be mainly due to the surface conduction effect.

We propose to interpret the permeability dependence of electrokinetic coupling coefficient using the capillary model and the Carman-Kozeny law. Indeed

$\mathrm{k}=\mathrm{c} \Phi \mathrm{m}^{2} / \mathrm{t}^{2}$ where $\mathrm{m}=\Phi / \mathrm{A}_{\mathrm{s}}$ is the hydraulic radius. Tortuosity can be taken into account through the formation factor $\mathrm{F}$ using $\mathrm{t}^{2}=\Phi \mathrm{F}$ which implies $\mathrm{k}=\mathrm{c} \mathrm{m}^{2} \mathrm{~F}^{-1}$ [Wyllie and Spangler, 1952; Paterson, 1983]. The electrokinetic coupling coefficient can be thus expressed as a function of permeability

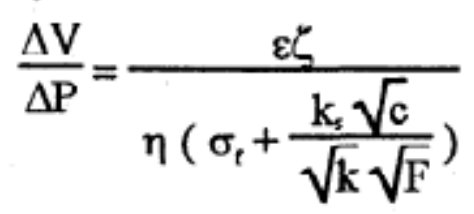

As the conduction current equilibrates the convection current which is constant, when sample conductivity is enhanced by surface conductivity the electrokinetic gradient is decreased. The dielectric constant of water is $\varepsilon / \varepsilon_{0}=80$ at $25^{\circ} \mathrm{C}$, the shear viscosity is $10^{-3} \mathrm{~Pa} \cdot \mathrm{s}$ at $20^{\circ} \mathrm{C}$ and the effect of temperature on $\mathrm{h}$ was taken into account.

\section{Fontainebleau sandstones}

Measurements of rock conductivity with different fluid conductivities allowed us to overestimate the surface conductance [Jouniaux and Pozzi, in press]. Ruffet [1993] measured surface conductance on Fontainebleau sandstones of $2 \times 10^{-10}$ to $8 \times 10^{-10} \Omega^{-1}$. Here $\mathrm{k}_{\mathrm{s}}$ was estimated to $5 \times 10^{-9} \Omega^{-1}$. The z potential was deduced as explained above and is $\zeta=-97 \mathrm{mV}$. Values of electrokinetic coupling coefficient computed from eq.(5) are shown in figure 1 (stars). This computation shows roughly the behavior of the electrokinetic coupling coefficient with permeability.

This model was used to predict the effect of permeability on electrokinetic coupling coefficient of the used samples when fluid conductivity is higher. These predictions are shown in figures 2 and 3 . The $\zeta$ potential was considered to be the same as before, that is an approximation. Indeed for pure quartz $\zeta$ potential can change from $-100 \mathrm{mV}$ for a fluid resistivity of $10^{3} \Omega . \mathrm{m}$ to $-50 \mathrm{mV}$ for a fluid resistivity of $10 \Omega . \mathrm{m}$ [Pride and Morgan, 1991]. A different value for $\zeta$ potential would not change the amplitude of variation of the electrokinetic coupling coefficient with permeability, but only its intrinsic value as shown by eq. (5). Note that for a given fluid conductivity the $\zeta$ potential is constant.

The electrokinetic coupling coefficient is proportional to $\mathrm{k}^{0.33}$ when fluid resistivity is $200 \Omega$.m (Fig. 2), is proportional to $\mathrm{k}^{0.27}$ when fluid resistivity is $100 \Omega \mathrm{m}$ (Fig. 3) and is proportional to $\mathrm{k}^{0.09}$ when fluid resistivity is $10 \Omega . \mathrm{m}$. The electrokinetic coupling coefficient is constant when fluid conductivity is $1 \Omega \mathrm{m}$ (Fig. 3). 


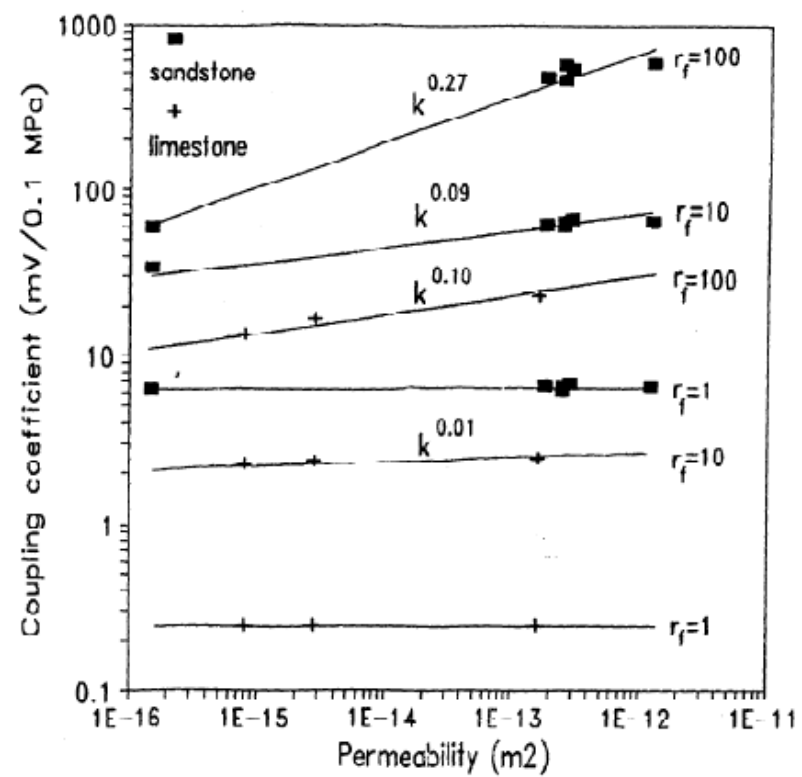

Figure 3. Predicted values of electrokinetic coupling coefficient versus permeability computed using eq.(5) for sandstones(filled square) and limestone(plus) with various fluid resistivities $\left(\mathrm{r}_{\mathrm{f}}\right)$. Straightlines are deduced from the model and slopes are proportional to $\mathrm{k}^{0.27}$, to $\mathrm{k}^{0.09}$, to $\mathrm{k}^{0.10}$ and to $\mathrm{k}^{0.01}$.

\section{Limestone sample}

Permeability of the limestone sample was decreased by deformation. The electrokinetic coupling coefficient was computed using eq.(5) in three states of deformation (C12, C11 and C10). The $\zeta$ potential was deduced from measurements on the non-deformed state (C12) when permeability was high using the Helmholtz-Smoluchowski equation and assuming that surface conductivity was not important. $\zeta$ potential was found to be $-4 \mathrm{mV}$. Surface conductance $\mathrm{k}_{\mathrm{s}}$ was estimated to $5 \times 10^{-10} \Omega^{-1}$. Values of electrokinetic coupling coefficient computed from eq.(5) are shown in figure 2 (stars). This computation shows that the electrokinetic coupling coefficient is proportional to $\mathrm{k}^{0.23}$ when fluid resistivity is $200 \Omega \mathrm{m}$. The predicted effect of fluid conductivity is shown in figure 3. The electrokinetic coupling coefficient is proportional to $\mathrm{k}^{0.10}$ when fluid resistivity is $100 \Omega . \mathrm{m}$ and is proportional to $\mathrm{k}^{0.01}$ when fluid resistivity is $10 \Omega . \mathrm{m}$. The electrokinetic coupling coefficient is constant when fluid resistivity is $1 \Omega . \mathrm{m}$.

\section{Discussion and Conclusion}

Measurements of electrokinetic coupling coefficient on sandstones and limestone of various permeabilities show that the electrokinetic coupling coefficient is related to permeability. This correlation is strong when fluid resistivity is high. This behavior is explained by the contribution of surface conductivity. A capillary model allowed us to quantify this effect. This model can roughly account for the permeability dependence of electrokinetic coupling coefficient considering the surface conductivity effect. We used this model to compute the effect of permeability on electrokinetic coupling coefficient with various fluid conductivities. When fluid resistivity is high the electrokinetic coupling coefficient strongly depends on permeability and this dependence is more important for sandstones than for limestone. By chemical analysis calcium was found in fluid after flowing through the sandstone samples. This calcium is supposed to be responsible of a large part of surface conductivity in Fontainebleau sandstones. When fluid is more conductive the effect of 
permeability is less important and for a fluid conductivity of $1 \Omega \mathrm{m}$ this model shows that the electrokinetic coupling coefficient is no longer dependent on permeability. Models usually use an average water resistivity

of $10^{2} \Omega$.m in the Earth's crust, that means that the electrokinetic coupling coefficient will be affected by changes of permeability. In some area where sea water is predominant, with a resistivity less than $1 \Omega$.m, it is likely that the electrokinetic coupling coefficient will not be affected by changes of permeability.

Acknowledgments. This study is a collaboration with ENSAM (Laboratoire de mecanique des structures). We thank the referees for their very useful comments and suggestions. This research was supported by ANDRA and the GRECOgeomateriaux. This is a CNRS-INSU-DBT contribution ${ }^{\circ}{ }^{5}$, theme fluides et failles.

\section{References}

Antraygues, P. and Aubert, M., Self Potential Generated by Two-Phase Flow in a Porous Medium: Experimental Study and Volcanological Applications, J. Geophys. Res., 98, 22273-22281, 1993.

Aubert, M. et Dana, I., Interpretation des profils radiaux de polarisation spontane (PS) en volcanologie. Possibilites d'application de la methode PS a la surveillance des volcans actifs, Bull. Soc. geol. France, t. 165, 2, 113-122, 1994.

Bernard, P., Plausibility of Long Distance Electrotelluric Precursors to Earthquakes, J. Geophys. Res., 97, 17531-17546, 1992.

Broz, Z. and Epstein, N., Electrokinetic flow through porous media composed of fine cylindrical capillaries, J. Colloid and Interface Science, 56, 605-612, 1976.

Corwin, R.F. and Hoover D.B., The self potential method in geothermal exploration, Geophysics, 44, 226245, 1979.

De Groot, S.R. and Mazur, P., Non equilibrium thermodynamics, North Holland (Ed.), Amsterdam, 1962.

Dukhin, S.S. and Derjaguin, B.V., Surface and Colloid Science, 7, ed. E. Matijevic, John Wiley and sons, NY, 1974.

Ishido, T. and Mizutani, H., Experimental and theoretical basis of electrokinetic phenomena in rock-water systems and its applications to geophysics, J. Geophys. Res., 86, 1763-1775, 1981.

Jouniaux, L. and Pozzi, J.P., Streaming potential and permeability on satured sandstones under triaxial stress : consequences for electrotelluric anomalies prior to earthquakes, J. Geophys. Res., in press.

Levine, S., Marriott, J.R., Neale, G. and Epstein, N., Theory of Electrokinetic Flow in Fine Cylindrical Capillaries at High Zeta-Potentials, J. Colloid Interface Sci., 52, 136-149, 1975.

Li, H.C., and De Bruyn P.L., Electrokinetic and adsorption studies on quartz, Surface Science, 5, 203-220, 1966.

Merkler, G.P., Militzer, H., Hötzl, H., Armbruster, H. and Brauns, J. (Eds), Detection of subsurface flow phenomena, Lecture notes in Earth Sciences, vol. 27, Springer-Verlag (Ed), 1989.

Mizutani, H., Ishido, T., Yokokura, T. and Ohnishi S., Electrokinetic phenomena associated with earthquakes, Geophys. Res. Lett., 3, N 7, 365-368, 1976.

Morat, P. et Le Mouël, J.L., Signaux électriques engendrés par des variations de contrainte dans des roches poreuses non saturées, C. R. Acad. Sci. Paris, t. 315, Série II, 955-963, 1992.

Morgan, F.D., Williams, E.D. and Madden, T.R., Streaming potentials properties of Westerly granite with applications, J. Geophys. Res., 94, 12449-12461, 1989.

Nourbehecht, B., Irreversible thermodynamic effects in inhomogeneous media and their applications in certain geoelectric problems, Ph. D. Thesis, M.I.T., Cambridge, USA, 1963.

Overbeek, J.Th. G., Electrochemistry of the double layer, Colloid Science, vol. 1, Irreversible Systems, Ed. H.R. Kruyt, Elsevier, New York, 115-193, 1952.

Paterson, M.S., The equivalent channel model for permeability and resistivity in fluid-saturated rock- A reappraisal, Mechanics of Materials, 2, 345-352, 1983.

Pfannkuch, H.O., On the correlation of electrical conductivity properties of porous systems with viscous 
flow transport coefficients, in Fundamentals of Transport Phenomena in Porous Media, 42-54, Elsevier, NY, 1972.

Pride, S. R. and Morgan, F. D., Electrokinetic dissipation induced by seismic waves, Geophysics, 56, 914925, 1991

Rice, C.L. and Whitehead, R., Electrokinetic Flow in a Narrow Cylindrical Capillary, J. Phys. Chem., 69, 4017-4123, 1965.

Ruffet, C., La conductivité électrique complexe dans quelques roches crustales, Thèse Université Louis Pasteur, Strasbourg, 1993.

Somasundaran, P. and Kulkarni, R.D., A new streaming potential apparatus and study of temperature effects using it, J. Colloid and Interface Science, 45, 591-600, 1973.

Stern, O., Zür theorie der elektrolischen doppelschicht, Z. Elektrochem., 30, 508, 1924.

Wyllie, M.R.J. and Spangler, M.B., Application of electrical resistivity measurements to problem of fluid flow in porous media, Bull. AAPG, 36, N², 359-403, 1952.

Zlotnicki, J. and Le Mouël, J.L., Possible electrokinetic origin of large magnetic variations at La Fournaise volcano, Nature, 343, 633-635, 1990.

L. Jouniaux and J.-P. Pozzi, Laboratoire de Géologie \& CNRS URA 1316, École Normale Supérieure, 24 rue Lhomond, 75231 Paris Cédex 05, France, (e-mail : pozzi@magnetit.ens.fr). 